\title{
COMPORTAMENTO PEDAgÓgico dOS INSTRUTORES DE AULAS DE GRUPO DE FITNESS DE LOCAUZADA
}

\author{
Susana Carla Alves Franco ${ }^{1}$ sfranco@ esdrm.pt \\ José de Jesus Fernandes Rodrigues ${ }^{1}$ jrodrigues@ esdrm.pt \\ Marta Castañer i Balcells² castaner@ inefc.uld.es
}

doi:10.3900/fpj.7.4.251.p

Franco SCA, Rodrigues JJF, Balcells MC. Comportamento pedagógico dos instrutores de aulas de grupo de fitness de localizada. Fit Perf J. 2008 jul-ago; $7(4): 251-63$.

\section{RESUMO}

Introdução: Este estudo teve como objetivo realizar uma aplicação piloto do novo instrumento desenvolvido, Sistema de $O$ bservação do Comportamento dos Instrutores de Fitness - Aulas de G rupo (SO CIF), pretendendo-se identificar e descrever quais as tendências comportamentais dos instrutores de fitness nas aulas de grupo, designadamente de localizada. Materiais e Métodos: Foram observadas sessões de localizada, com conteúdo de treino de resistência muscular. Foi efetuado o registro da duração dos comportamentos, através do instrumento SO CIF. Resultados: Foram encontrados valores excelentes de fidelidade intra-observador. Discussão: Verificou-se que: quando confrontados os resultados deste estudo com os de outros estudos, independente do contexto, os do is principais comportamentos dos professores, treinadores ou instrutores são a informação e/ou observação, parecendo que os comportamentos restantes apresentam variações em termos de ocorrência; existem alguns comportamentos que os sujeitos nunca manifestaram; os comportamentos positivos predominam em relação aos negativos; as instruto ras utilizam comportamentos que são importantes como estratégias pedagógicas para reter os alunos à prática de exercício, quais sejam, a Afetividade positiva, avaliação positiva, pressão e conversas com alunos. 0 s comportamentos evidenciam uma variação na sua ocorrência, de sujeito para sujeito. O s comportamentos parecem mudar a sua ocorrência de acordo com as fases da aula. O s comportamentos aparentam ser influenciados pela posição de realização dos exercícios. As instrutoras, durante a aula, passam a maioria do seu tempo a realizar exercício físico.

\section{PALAVRAS-CHAVE}

Comportamento, Aptidão Física, Exercício.

\footnotetext{
${ }^{1}$ Escola Superior de Desporto de Rio Maior - Rio Maior - Portugal

${ }^{2}$ Institut Nacional d'Educació Física de Catalunya - Lleida - Espanha
} 
FITNESS INSTRUCTORS' PEDAGOGICAL BEHAVIOUR IN RESISTANCE TRAINING FITNESS GROUP CLASSES

\section{ABSTRACT}

Introduction: The aim of this pilot study is to make an application of the new developed instrument Fitness Instructors' Behaviour 0 bservation System - G roup Classes (SO CIF), and to describe which, in Resistance Training classes, the behaviour instructor's tendencies are. Materials and Methods:There were observed Resistance Training sessions, in group classes, with the content of resistance strength. We registered the behaviours duration through an observation system of the instructors (SO CIF). Results: It was guaranteed excellent values of reliability intra -observer. Discussion: We have concluded that: When we confronted the results of this study with other studies, independently of the context, the two principal behaviours of the teachers, coaches or instructors are Information and/or observation, and the other behaviours present an variable occurrence; there are some behaviours that are never manifested by the instructors; the positive behaviours prevail in relation to the negatives; the instructors use behaviours that are important as pedagogical strategies to retain the participants to the exercise practice, such as positive affectivity, praise, hustle and conversation with participants. The behaviours seem to vary between instructors; the instructors' behaviour seems to change their occurrence in agreement with the class' phases. The instructors' behaviour seems to be influenced by the position of the exercises. The instructors, during the class, spend most of the time in exercise.

\section{KEYWORDS}

Behavior, Physical Fitness, Exercise.

\section{LA CONDUCTA PEDAGÓGICA DE LOS INSTRUCTORES DE CLASES DE GRUPO DE FITNESS DE LOCALIZADA}

\section{RESUMEN}

Introducción: El objetivo de este estudio piloto es hacer una aplicación de lo Sistema de O bservación de la Conducta de los Instructores de Fitness - Clases de G rupo (SO CIF), y describir cuáles son las tendencias de conducta de los instructores en clases de localizada. Materiales y Métodos: Han sido observadas sesiones de localizada, con el contenido de la resistencia muscular. Se registraron las duraciones de los comportamientos a través de lo instrumento SO CIF. Resultados: Se ha encontrados excelentes valores de concordancia intra-observador. Discusión: Se ha concluido que: Cuando confrontados los resultados de este estudio con otras pesquisas, independientemente del contexto, los dos principales comportamientos de los profesores, entrenadores o instructores son la Información y/o la O bservación, y las otra conductas presentan una ocurrencia variable; Hay algunos comportamientos que nunca se manifiestan en los instructores; Hay una prevalencia de comportamientos positivos en relación con los negativos; Los instructores utilizan comportamientos que son importantes como estrategias pedagógicas para retener los alumnos en la práctica de ejercicio, como por ejemplo: afectividad positiva, evaluación positiva, presión y conversas con los alumnos. Los comportamientos parecen variar entre los instructores. Los comportamientos de los instructores parecen cambiar su ocurrencia de acuerdo con las fases de la clase. El comportamiento de los instructores parece ser influenciado por la posición de los ejercicios. Los instructores, durante la clase, están la mayor parte del tiempo en ejercicio.

\section{PALABRAS CLAVE}

Conducta, Acondicionamiento Físico, Ejercicio.

\section{INTRODUÇÃO}

A observação sistemática dos comportamentos do treinador durante os treinos é um passo para a compreensão do processo de treino num determinado contexto ${ }^{1}$. A observação sistemática é reconhecida por vários autores como sendo um efetivo instrumento de pesquisa na descrição quantitativa dos comportamentos do treinador de Desporto ou professor de Educação Física 2,3,4, e o uso dos dados obtidos através deste tipo de instrumento tem dado ao processo de treino uma base científica que os treinadores podem utilizar para facilitar o desenvolvimento dos atletas e das equipes ${ }^{5}$.

Existem vários sistemas de observação do comportamento dos treinadores de Desporto ou professores de
Educação Física ${ }^{6,7,8,9}$. Lacy $\&$ G oldston ${ }^{10}$ referem que é importante que os investigado res utilizem instrumentos de observação sistemática para estudar o comportamento dos treinadores durante a sua prática em vários desportos, de modo a se poder estabelecer uma base de dados representativa dos comportamentos dos treinadores em variadas situações desportivas, como já se tem vindo a fazer em vários estudos ${ }^{11,12,13,14,15,16,17,18}$. Lacy \& G oldston $^{\mathbf{1 0}}$ acrescentam ainda que é necessário que os sistemas de observação, para aumentarem a sua validade e fidelidade, levem em conta 0 desporto e a especificidade cultural em causa, como é, por exemplo, o caso do instrumento criado por Brewer \& J ones ${ }^{19}$, que consistiu numa adaptação do sistema de observação de Lacy \& Darst ao 
contexto do rugby. No entanto, até o momento, na área do fitness, não foi encontrado nenhum estudo acerca dos aspectos pedagógicos relacionados com a intervenção dos instrutores de fitness, nomeadamente acerca do comportamento dos instrutores de atividades de fitness, nem nenhum instrumento específico para tal.

Este estudo teve como objetivo realizar uma aplicação piloto do novo instrumento desenvolvido Sistema de 0 bservação do Comportamento dos Instrutores de Fitness - Aulas de $\mathrm{Grupo}^{20}$, pretendendo-se identificar e descrever quais as tendências comportamentais dos instrutores de fitness nas aulas de grupo, designadamente de localizada.

Sabe-se que noutros contextos que não no fitness, existem variáveis que podem influenciar o comportamento dos treinadores/professores, como, por exemplo, as fases da aula ${ }^{13}$, não tendo sido encontrado nenhum estudo acerca do comportamento dos instrutores de fitness, designadamente em aulas de grupo. Por outro lado, segundo Francis $\&$ Seibert ${ }^{21}$, um dos estilos de ensino predominante nas aulas de grupo de fitness é o Estilo de Ensino por Comando, o qual tem como característica o fato dos instrutores estarem predominantemente em exercício físico, durante o qual adotam diversas posições (em pé, sentado, deitado lateral, deitado ventral, deitado dorsal, de gatas, sentado com flexão do tronco ou da cabeça, em pé com flexão do tronco ou da cabeça), as quais poderão levar a que os instrutores possam ter uma melhor ou pior visualização dos alunos. Desse modo, este estudo consta da análise dos comportamentos das instrutoras de fitness durante a lecionação de aulas de grupo de localizada, na qual são colocadas as seguintes questões:

- Q uais serão os comportamentos mais freqüentes destas instrutoras?

- Q uais serão os comportamentos menos freqüentes destas instrutoras?

- Q ual será a razão existente entre os comportamentos positivos e os negativos?

- Será que os comportamentos variam a sua ocorrência de sujeito para sujeito?

- Será que os comportamentos mudam de acordo com as fases da aula?

- Será que comportamentos são influenciados pela posição de realização dos exercícios?

- Será que as instrutoras passam a maior parte da aula realizando exercícios?

\section{MATERIAIS E MÉTODOS}

\section{Amostra}

0 método de amostragem utilizado para estudar os comportamentos dos instrutores de aulas de localizada foi 0 da Amostragem por Conveniência, o qual não permite extrapolar os resultados e conclusões obtidas para o universo em causa, mas que pode ser útil num estudo piloto, por exemplo para testar as primeiras versões de um instrumento de pesquisa ${ }^{22}$, como é o caso deste estudo.

Existem diversas variáveis que podem ter influência no comportamento dos instrutores. O s sujeitos da amostra foram selecionados segundo os seguintes critérios:

- Serem do sexo feminino;

- Serem do Concelho de Lisboa (Portugal), pois, embora não se conheça nenhum estudo acerca do assunto, as influências culturais da região poderiam eventualmente ter influência no comportamento dos instrutores;

- Não serem licenciadas na área das Ciências do Desporto, mas terem um curso técnico-profissional específico, dado que a formação inicial parece ter influência no conhecimento e, consequentemente, no comportamento dos treinadores/professores $23,24,25,26$.

- Terem, pelo menos, cinco anos de experiência profissional, sendo esta classificação baseada no autor Berliner ${ }^{25}$, embora esta seja apresentada para o contexto da Educação Física. Segundo Moreira \& Januário ${ }^{27}$, a experiência profissional parece ter influência no comportamento dos professores.

Foram escolhidas apenas aulas de localizada, pois, segundo alguns autores ${ }^{\mathbf{8}, 28}$, o tipo de atividades pode ter influência no comportamento dos treinadores/professores. A escolha da atividade de localizada, e não de outra, entre as várias existentes na área do fitness, deveu-se ao fato de esta ser uma das mais praticadas atualmente nos ginásios de Portugal.

Apenas foram escolhidas aulas de nível intermédio, queé o nível majoritário das aulas de localizada em Portugal, pois, segundo Rodrigues ${ }^{15}$, o nível (divisão) com que se trabalha parece ter influência no comportamento dos treinadores.

Após verificado se os sujeitos cumpriam os critérios acima mencionados, foram gravadas em vídeo (imagem e som) três aulas de localizada de nível intermédio, lecionadas por cada uma das três instrutoras de aulas de grupo de fitness, em três ginásios do Concelho de Lisboa (Portugal), totalizando, assim, nove aulas. Apesar de terem sido gravadas três aulas de cada instrutora, apenas foi codificada a terceira aula de cada uma delas, de modo a reduzir 0 efeito da interferência que 0 observador, a câmara e o microfone podem eventualmente exercer sobre as instrutoras e os alunos.

As instrutoras tinham idades compreendidas entre $28 \mathrm{e}$ 34 anos $(30,33 \pm 3,21)$, e experiência profissional nas aulas de grupo de fitness entre 5 e 14 anos $(8,33 \pm 4,93)$.

Todas elas eram não-licenciadas na área das C iências do Desporto, mas já tinham frequentado um curso técni- 
co-profissional de especialização em aulas de grupo de fitness. Dos cursos que as instruto ras freqüentaram, todos tinham como conteúdo a localizada, assim como outras atividades. Além dos cursos que freqüentaram, as instrutoras dizem continuar a atualizar os seus conhecimentos indo a um ou dois workshops/ convenções por ano.

A freqüência de lecionação de aulas de localizada variou entre duas e sete vezes por semana $(4,67 \pm 2,52)$. Todas as instrutoras lecionavam aulas de outras atividades de grupo de fitness. A freqüência de lecionação de aulas de grupo de fitness (independentemente da atividade) variou entre 8 e 12 aulas por semana $(10,00 \pm 2,00)$.

As instrutoras trabalhavam nas instituições onde foram gravadas há uma média de 6,00 2,65 anos (entre 4 e 9 anos) e apenas uma delas não trabalha noutro ginásio. N enhuma exercia outra atividade profissional além da de instrutora de aulas de grupo de fitness.

\section{Variáveis}

Relativamente ao comportamento das instrutoras de fitness (variável dependente), neste estudo foram consideradas as seguintes variáveis independentes:

- as fases da aula (aquecimento; fase fundamental; alongamento);

- 0 exercício físico das instrutoras;

- A visualização das instrutoras relativamente aos alunos, derivada da posição dos exercícios que esta se encontra a realizar.

Malek et al. ${ }^{23}$ verificaram que a formação inicial tem influência no conhecimento dos profissionais de fitness (treinadores personalizados). Piéron ${ }^{25}$ refere que o comportamento dos professores é influenciado pelo seu conhecimento e experiência profissional, entre outros fatores. Em alguns estudos, as variáveis formação inicial $^{\mathbf{2 4 , 2 6}}$, experiência profissional ${ }^{27}$, tipo de atividades ${ }^{\mathbf{8} 28}$, nível (divisão) dos praticantes ${ }^{15}$, revelaram ter influência no comportamento dos treinadores/professores. Assim, estas variáveis, e eventualmente outras, poderão ter influência no comportamento dos instrutores de aulas de grupo de fitness, pelo que foram controladas as seguintes variáveis: formação inicial do instrutor (não-licenciados na área das Ciências do Desporto, mas com um curso técnico-profissional de especialização em aulas de grupo de fitness); experiência profissional do instrutor (mínimo de 5 anos, baseado na definição de Berliner ${ }^{25}$, acerca de um professor expert); tipo de atividade lecionada (localizada); nível de aula lecionada (nível intermédio); gênero do instrutor (feminino); região do país (Concelho de Lisboa).

\section{Instrumento}

Para estudar o comportamento dos instrutores de localizada, foi utilizado o Sistema de 0 bservação do
Comportamento dos Instrutores de Fitness - Aulas de Grupo 20.

Este sistema de observação foi inspirado no Sistema de O bservação do Comportamento do Treinador e do Atleta (SO TA $)^{8}$, baseando-se apenas na estrutura de comportamentos do treinador. A especificidade da intervenção dos instrutores nas aulas de grupo de fitness, como, por exemplo, o fato da realização de exercício físico dos instrutores ser quase uma constante em muitos deles, levou à necessidade de criação de um sistema de observação mais adaptado para a análise dos comportamentos destes profissionais desta área.

Este sistema de observação permite recolher informação acerca do comportamento dos instrutores de aulas de grupo de fitness, podendo servir de instrumento para ser utilizado como análise dos instrutores a nível profissional ou para ser utilizado em futuras pesquisas. Por estar adequado a uma determinada realidade, a sua utilização é possível de se concretizar na maioria das atividades de grupo de fitness (aeróbica, step, slide, hip hop, hidroginástica, localizada, combat, indoor cycling, stretching,...).

O sistema de observação é constituído por seis dimensões de comportamento dos instrutores de aulas de grupo de fitness:

- Instrução;

- Interação;

- Atividade;

- Controle;

- O rganização;

- O utros Comportamentos.

As dimensões são constituídas pelas seguintes categorias de análise do comportamento:

- Instrução

- Informação Com Exercício (IE);

- Informação Sem Exercício (I);

- Demonstração Com Informação (DI);

- Demonstração Sem Informação (D);

- Correção Com Exercício (CE);

- Correção Sem Exercício (C);

- Avaliação Positiva Com Exercício (Av+E);

- Avaliação Positiva Sem Exercício (Av+);

- Avaliação Negativa Com Exercício (Av-E);

- Avaliação Negativa Sem Exercício (Av-);

- Q uestionamento Com Exercício (Q E);

- Q uestionamento Sem Exercício (Q );

- Interação

- Afetividade Positiva Com Exercício (Af+E);

- Afetividade Positiva Sem Exercício (Aft);

- Afetividade N egativa Com Exercício (Af-E);

- Afetividade $N$ egativa Sem Exercício (Af-);

- Pressão Com Exercício (PE);

- Pressão Sem Exercício (P); 
- Conversas Com Alunos Com Exercício (CAE);

- Conversas Com Alunos Sem Exercício (CA);

- Conversas $\mathrm{Com} O$ utros $\mathrm{Com}$ Exercício (CO E);

- Conversas Com $\mathrm{O}$ utros Sem Exercício (C O );

- Atividade

- Exercício Físico Participativo (EFP);

- Exercício Físico Independente (EFI);

- Controle

- O bservação Com Exercício (O E);

- O bservação Sem Exercício (O );

- Atenção às Intervenções Verbais dos Alunos C om Exercício (AIVAE);

- Atenção às Intervenções Verbais dos Alunos Sem Exercício (AIVA);

- Atenção às Intervenções Verbais de 0 utros $\mathrm{Com}$ Exercício (AIVO E);

- Atenção às Intervenções Verbais de 0 utros Sem Exercício (AIVO);

- O rganização

- G estão Com Exercício (GE);

- G estão Sem Exercício (G);

- O utros Comportamentos

- O utros Comportamentos (O C).

Para realizar o registro, a partir do visionamento de vídeo, foi utilizado o método de Registro da Duração ${ }^{29,30}$ de cada episódio de comportamento.

Para testar a fidelidade intra-observador, relativamente ao SO C IF, foi feita a observação de um vídeo de localizada, tendo sido utilizado o método de Registro da Duração ${ }^{29,30}$. Tal como sugerido por Mars ${ }^{31}$, o mesmo observador analisou os mesmos períodos do vídeo em duas ocasiões distintas, distando as observações pelo menos uma semana, neste caso, oito dias.

Após a análise do vídeo em duas ocasiões, procedeu-se à determinação do nível de fidelidade intraobservador, utilizando o teste Kappa de Cohen. Foram aceitos valores de fidelidade superiores a $75 \%$, sendo estes considerados de excelente concordância ${ }^{32}$. Das 33 categorias, 23 apresentaram valores de fidelidade de $100 \%$. As 10 categorias restantes apresentaram valores superiores a $95 \%$, tendo os valores de Kappa de Cohen variado entre 0,951 e 1,000, ou seja, entre $95,1 \%$ e $100 \%$.

\section{Equipamentos e procedimentos}

Para verificar qual o perfil de comportamento das instrutoras de aulas de localizada, foi utilizada a observação com gravação em vídeo (som e imagem). Para realizar as gravações de vídeo, foi pedida autorização ao responsável de cada um dos ginásios, assim como às instrutoras e alunos.

A equipe de gravação foi constituída por dois sujeitos, tendo sido previamente combinados e treinados todos os procedimentos a realizar durante as gravações.

O conteúdo das fitas de vídeo foi transferido para um $P C$, através do software Windows M ovie Maker, tendo o visionamento sido realizado através do software Windows Media Player, o qual tem um cronômetro incorporado.

\section{Tratamento dos dados}

Após verificada a quantidade de tempo em cada categoria de comportamento por parte das instrutoras (em segundos), estes valores foram convertidos em percentagem para posterior tratamento estatístico, tendo sido apenas utilizada a Estatística Descritiva.

Foram determinados a média e o desvio padrão da percentagem de tempo de cada dimensão e dos vários comportamentos das instrutoras de aulas de localizada, na totalidade da aula e por fase da aula, em exercício e sem estarem em exercício, assim como das várias categorias de comportamento nos exercícios propostos que proporcionam uma posição que permite ter uma boa visualização por parte das instrutoras (exercícios na posição deitado ventral, deitado dorsal, gatas, sentado com flexão do tronco ou da cabeça, em pé com flexão do tronco ou da cabeça) e nos exercícios propostos que proporcionam uma posição que não permite ter uma boa visualização por parte das instrutoras (exercícios na posição de deitado lateral, sentado ou em pé).

Foi também calculada a razão entre os comportamentos positivos (Av+E, Av+, Af+E e Af+) e os comportamentos negativos (Av-E, Av-, Af-E e Af-).

Por fim, foi calculado o somatório dos comportamentos considerados por $C$ arron et al. ${ }^{33}$ e por Massey et al. ${ }^{14}$, como sendo estratégia pedagógica dos instrutores para motivação e retenção de clientes ( $A v+E, A v+, A f+E, A f+$, $P E, P, C A E$ e $C A)$

Quadro 1 - Percentagens de cada dimensão de comportamentos, na totalidade da aula

\begin{tabular}{lcccc}
\hline Dimensões de Comportamento & média \pm desvio padrão & S1 & S2 & S3 \\
\hline Instrução & $60,7 \pm 4,8$ & 66,0 & 56,5 & 59,6 \\
Interação & $8,1 \pm 3,8$ & 5,6 & 6,1 & 12,5 \\
Atividade & $4,0 \pm 2,8$ & 5,8 & 0,8 & 5,4 \\
Controle & $22,1 \pm 6,8$ & 17,9 & 30,0 & 18,5 \\
Organização & $4,5 \pm 1,3$ & 4,2 & 5,9 & 3,3 \\
Outros Comportamentos & $0,7 \pm 0,1$ & 0,6 & 0,7 & 0,7 \\
\hline
\end{tabular}

S1: Sujeito 1; S2: Sujeito 2; S3: Sujeito 3 


\section{Limitações do estudo}

Uma das limitações deste estudo reside no fato da amostra ser relativamente pequena (apenas uma aula de cada uma das 3 instrutoras), pelo que não é possível fazer uma caracterização dos instrutores de localizada que possa ser generalizada, podendo os dados não ser representativos do perfil de comportamentos de cada sujeito, sendo este um estudo piloto acerca deste assunto.

Apenas foram controladas as variáveis gênero, formação inicial e anos de experiência profissional das instrutoras, região do país, atividade e ainda a variável nível da aula, podendo no entanto existir outras variáveis que possam ter influência no comportamento dos instrutores de aulas de grupo de fitness (ex: nível; gênero e idade dos alunos; número de alunos²7; instituição; horário; localidade).

0 fato das aulas terem sido gravadas em vídeo poderá ter alterado o comportamento dos alunos e das instrutoras. Embora não se tenha tido como objetivo estudar o comportamento dos alunos, é feita referência ao fato do comportamento dos alunos ser alterado, pois isto poderá trazer como conseqüência a alteração do comportamento dos professores ${ }^{27}$.

\section{RESULTADOS}

O s resultados do estudo são apresentados nos Q uadros 1 a 7.

\section{DISCUSSÃO}

Seguidamente, são a presentados os resultados obtidos relativos a os comportamentos das três instrutoras de fitness observadas durante a lecionação de aulas de localizada.

Como se pode constatar no $Q$ uadro 1 , a dimensão que apresenta uma maior percentagem de tempo, em todas as instrutoras, é a Instrução $(60,69 \pm 4,84 \%)$, seguindo-se a dimensão Controle $(22,10 \pm 6,83 \%)$. A dimensão com menor percentagem é 0 utros Comportamentos $(0,66 \pm 0,10 \%)$. As restantes dimensões variam um pouco de sujeito para sujeito, mas em termos médios a dimensão Interação $(8,06 \pm 3,82 \%)$ surge em 3.0 lugar, seguida da dimensão 0 rganização $(4,47 \pm 1,31 \%)$ e da dimensão Atividade $(4,01 \pm 2,77 \%)$.

Como se pode verificar no $Q$ uadro 2 , o comportamento que em média teve uma maior percentagem de tempo foi a IE $(32,74 \pm 7,97 \%)$, seguindo-se a OE $(16,65 \pm 1,88 \%)$. Estes dois comportamentos ocupam cerca de metade da aula $(49,39 \%)$, e estes, juntamente com a Instrução Sem Exercício e C om a DI, ocupam cerca de $2 / 3$ da aula $(66,78 \%)$.

Comparados estes resultados com os de outros estudos $s^{8,11,12,13,14,15,16,17,18,34,35}$, verifica-se que os dois comportamentos mais duradouros destas instruto ras são também os comportamentos mais freqüentes encontrados por outros autores (Informação e O bservação), com a diferença que as instrutoras do presente estudo se encontram em exercício, o que é característico deste tipo de atividade.

As informações que as instrutoras fornecem quando estão realizando exercícios físicos podem ter vários objetivos, quais sejam: a apresentação de um novo exercício; a explicação acerca de como realizar o novo exercício; a apresentação dos erros a não realizar no novo exercício; a variação da velocidade do exercício; a colocação de um elemento de variação num exercício; a apresentação do número de repetições de um exercício; o relembrar das

Quadro 2 - Percentagens de cada categoria de comportamentos, na totalidade da aula

\begin{tabular}{lcccc}
\hline Comportamentos & $\begin{array}{c}\text { média } \pm \\
\text { desvio padrão }\end{array}$ & S1 & S2 & S3 \\
\hline IE & $32,7 \pm 8,0$ & 33,6 & 24,4 & 40,2 \\
I & $8,8 \pm 5,7$ & 14,6 & 8,6 & 3,2 \\
DI & $8,2 \pm 1,6$ & 9,1 & 6,9 & 9,9 \\
D & $0,3 \pm 0,2$ & 0,3 & 0,2 & 0,5 \\
CE & $1,6 \pm 0,2$ & 1,4 & 1,9 & 1,7 \\
C & $5,6 \pm 5,6$ & 3,7 & 11,8 & 1,1 \\
Av+E & $0,9 \pm 0,6$ & 1,3 & 0,1 & 1,2 \\
Av+ & $0,5 \pm 0,2$ & 0,7 & 0,3 & 0,3 \\
Av-E & $0,1 \pm 0,1$ & 0,1 & 0,2 & 0,1 \\
Av- & $0,1 \pm 0,0$ & 0,1 & 0,1 & 0,1 \\
QE & $0,9 \pm 0,3$ & 0,6 & 0,9 & 1,2 \\
Q & $0,6 \pm 0,5$ & 0,6 & 1,1 & 0,1 \\
Af+E & $1,4 \pm 1,3$ & 0,3 & 1,1 & 2,9 \\
Af+ & $1,1 \pm 0,5$ & 0,5 & 1,3 & 1,4 \\
Af-E & $0,3 \pm 0,4$ & 0,1 & 0,1 & 0,7 \\
Af- & $0,1 \pm 0,1$ & 0,2 & 0,2 & 0,0 \\
PE & $1,9 \pm 1,4$ & 2,7 & 0,3 & 2,6 \\
P & $0,6 \pm 0,9$ & 1,6 & 0,1 & 0,1 \\
CAE & $0,8 \pm 0,7$ & 0,0 & 0,9 & 1,4 \\
CA & $1,7 \pm 1,4$ & 0,2 & 2,0 & 2,9 \\
COE & $0,0 \pm 0,0$ & 0,0 & 0,0 & 0,0 \\
CO & $0,2 \pm 0,2$ & 0,0 & 0,1 & 0,4 \\
EFP & $0,0 \pm 0,0$ & 0,0 & 0,0 & 0 \\
EFI & $4,0 \pm 2,8$ & 5,8 & 0,8 & 5,4 \\
OE & $16,5 \pm 1,9$ & 14,7 & 18,5 & 16,7 \\
O & $5,2 \pm 5,0$ & 3,0 & 10,9 & 1,8 \\
AIVAE & $0,0 \pm 0,0$ & 0,0 & 0,0 & 0,0 \\
AIVA & $0,2 \pm 0,3$ & 0,2 & 0,6 & 0,0 \\
AIVOE & $0,0 \pm 0,0$ & 0,0 & 0,0 & 0,0 \\
AIVO & $0,0 \pm 0,0$ & 0,0 & 0,0 & 0,0 \\
GE & $0,4 \pm 0,3$ & 0,5 & 0,7 & 0,2 \\
G & $4,0 \pm 1,1$ & 3,7 & 5,2 & 3,2 \\
OC & $0,7 \pm 0,1$ & 0,6 & 0,7 & 0,7 \\
\hline SI:SUl & $2,53: 5 v i 0$ & & &
\end{tabular}

S1: Sujeito 1; S2: Sujeito 2; S3: Sujeito 3 
componentes críticas ou dos erros mais comuns. Deixamos as seguintes questões em aberto:

- Será que os instrutores optam por reduzir o tempo em demonstração, de forma a maximizar o tempo de prática dos alunos, e preferem continuar a explicar 0 exercício enquanto os alunos já estão em atividade física? Apesar de ser aumenta do o tempo de prática, em termos de aprendizagem não será mais difícil para os alunos perceberem a informação dada pelo instrutor enquanto estão a realizar exercício, já que têm que prestar atenção a duas tarefas ${ }^{36}$ ?

- Por que é que os instrutores, no meio do exercício, relembram as componentes críticas ou erros mais comuns? Será por que, como não querem evidenciar algum erro que um ou mais alunos estejam cometendo, optam por, em vez de corrigir, dar informação? As categorias com valores menos elevados ( $\mathrm{COE}$, EFP, AIVAE, AIVOE, AIVO ) são iguais nos três sujeitos, sendo neste caso de $0,00 \%$. As restantes categorias variam a sua ordem de sujeito para sujeito, não existindo a mesma quantidade de cada tipo de comportamento em cada uma das instrutoras, parecendo que estas adotam estratégias pedagógicas diferentes durante a lecionação das suas aulas.

A inexistência de EFP pode ter estado relacionada com o tipo de conteúdos programados, pois, por exemplo, não foram realizados exercícios em grupos.

A razão entre os comportamentos positivos (Avaliação e Afetividade Positiva, estando ou não em exercício) e os comportamentos negativos (Avaliação e Afetividade Negativa, estando ou não em exercício) é de cerca de 6 para $1(5,92 / 1)$, predominando assim os comportamentos positivos. Este fato é positivo, pois, segundo Carron et al. ${ }^{33}$, Mageau $\&$ Vallerand ${ }^{37}$ e C unha ${ }^{38}$, estes tipos de comportamento são importantes para motivar os alunos e, assim, os fidelizar ao exercício. Segrave \& Ciancio ${ }^{17}$, ao estudar o comportamento de um treinador de sucesso de futebol americano, verificaram que o elogio é um tipo de comportamento predominante nesse treinador, chamando à atenção para a importância que o elevado nível de elogios pode ter na motivação dos praticantes que treinam sem obrigação de o fazer, e o que o elevado nível de comportamentos positivos, em vez de negativos, pode ter no reforço da aprendizagem. No entanto, Claxton ${ }^{12}$, num estudo que realizou acerca dos comportamentos dos treinadores de tênis, com mais sucesso e com menos sucesso, verificou que os treinado res com menos sucesso davam mais elogios.

Sendo a Avaliação Positiva, a Afetividade Positiva, a Pressão e as Conversas Com Alunos, comportamentos que servem de estratégia pedagógica dos instrutores para retenção dos praticantes ${ }^{33}$, ao somar a média da percentagem destes comportamentos, estando ou não em exercício, verificamos que a percentagem total é de $8,81 \%$. Pelo fato de não encontrarmos nenhum estudo que permita fazer este somatório, não é possível estabelecer comparações, pelo que apenas deixamos a seguinte questão em aberto: este valor traduzirá eficácia pedagógica das instrutoras para retenção dos praticantes ou não?

A dimensão que têm maior predominância varia nas diferentes fases da aula (Q uadro 3). Em termos médios, a Instrução e o Controle são as dimensões que apresentam maiores percentagens, predominando 0 Controle no Aquecimento $(44,45 \pm 15,77 \%)$ e a Instrução na Fase Fundamental $(67,88 \pm 4,96 \%)$ e no Alongamento $(47,03 \pm 7,56 \%)$. No entanto, ao serem confrontados os sujeitos, verifica-se que, no Aquecimento, no Sujeito 1

Quadro 3 - Porcentagens de cada dimensão de comportamento, nas três fases da aula (Aquecimento, Fase Fundamental e Alongamento)

\begin{tabular}{|c|c|c|c|c|c|c|c|}
\hline \multirow[b]{2}{*}{ Fases da aula } & & \multicolumn{6}{|c|}{ Dimensão de Comportamentos } \\
\hline & & Instrução & Interação & Actividade & Controle & O rganização & $\begin{array}{c}\text { Outros } \\
\text { Comportamentos }\end{array}$ \\
\hline \multirow{4}{*}{ Aquecimento } & média \pm desvio padrão & $42,8 \pm 14,2$ & $4,3 \pm 2,6$ & $0,0 \pm 0,0$ & $44,5 \pm 15,8$ & $8,2 \pm 4,9$ & $0,2 \pm 0,4$ \\
\hline & S1 & 28,1 & 3,3 & 0,0 & 62,2 & 6,5 & 0,0 \\
\hline & $\mathrm{S} 2$ & 44,0 & 2,4 & 0,0 & 39,1 & 13,7 & 0,7 \\
\hline & S3 & 56,3 & 7,2 & 0,0 & 32,0 & 4,4 & 0,0 \\
\hline \multirow{4}{*}{$\begin{array}{l}\text { Fase } \\
\text { Fundamental }\end{array}$} & média \pm desvio padrão & $67,9 \pm 5,0$ & $8,7 \pm 2,8$ & $3,5 \pm 2,7$ & $16,1 \pm 4,5$ & $3,1 \pm 0,6$ & $0,7 \pm 0,3$ \\
\hline & S1 & 73,0 & 6,4 & 4,8 & 11,4 & 3,8 & 0,6 \\
\hline & $\mathrm{S} 2$ & 67,6 & 8,0 & 0,4 & 20,4 & 2,7 & 1,0 \\
\hline & S3 & 63,1 & 11,8 & 5,3 & 16,4 & 2,9 & 0,6 \\
\hline \multirow{4}{*}{ Alongamento } & média \pm desvio padrão & $47,0 \pm 7,6$ & $9,3 \pm 7,0$ & $10,2 \pm 9,6$ & $27,5 \pm 18,7$ & $5,2 \pm 1,9$ & $0,8 \pm 1,0$ \\
\hline & S1 & 50,9 & 2,5 & 15,5 & 25,4 & 5,1 & 0,6 \\
\hline & $\mathrm{S} 2$ & 38,3 & 4,6 & 2,8 & 47,1 & 7,2 & 0,0 \\
\hline & S3 & 51,9 & 20,7 & 12,2 & 9,8 & 3,4 & 1,9 \\
\hline
\end{tabular}

S1: Sujeito 1; S2: Sujeito 2; S3: Sujeito 3 
predomina o Controle $(62,20 \%)$, seguido da Instrução $(28,05 \%)$, enquanto que nos Sujeitos 2 e 3 predomina a Instrução (S2 =44,04\%; S3 $=56,30 \%$ ) e o Controle surge em 20 lugar ( $S 2=39,13 \% ; S 3=32,04 \%)$. Na Fase Fundamental predomina a Instrução em todos os sujeitos (S1 $=72,97 \% ; S 2=67,62 \% ; S 3=63,05 \%)$, surgindo 0 Controle em 20 lugar ( $\mathrm{S} 1=11,38 \%$; $\mathrm{S} 2=20,36 \%$; $\mathrm{S} 3=16,40 \%$ ). No Alongamento, no Sujeito 1 a Instrução é a dimensão com maior percentagem $(50,85 \%)$, seguindo-se o Controle $(25,42 \%)$, no Sujeito 2 o Controle têm a maior percentagem $(47,11 \%)$, seguido da dimensão Instrução (38,32\%), e no Sujeito 3 predomina a Instrução (51,92\%) seguida da Interação $(20,73 \%)$. Em termos médios, a dimensão com menor percentagem no Aquecimento é a Atividade $(0,00 \%)$, e na Fase Fundamental e no Alongamento é $\mathrm{O}$ utros $\mathrm{Comportamentos}$ $(0,74 \pm 0,25 \%$ e $0,83 \pm 0,99 \%$, respectivamente). Parece que os comportamentos têm alguma variação em função da fase da aula e em função dos sujeitos.

Ao analisar o $Q$ uadro 4 , verifica-se que o comportamento com maior média de percentagem de ocorrência difere nas várias fases da aula, sendo a OE 0 comportamento com uma maior média de percentagem no Aquecimento $(42,70 \pm 15,24 \%)$, a Instrução Com

Quadro 4 - Percentagens de cada categoria de comportamentos, nas três fases da aula (Aquecimento, Fase Fundamental e Alongamento)

\begin{tabular}{|c|c|c|c|c|c|c|c|c|c|c|c|c|}
\hline \multirow{3}{*}{ Comp. } & \multicolumn{12}{|c|}{ Fases da aula } \\
\hline & \multicolumn{4}{|c|}{ Aquecimento } & \multicolumn{4}{|c|}{ Fase Fundamental } & \multicolumn{4}{|c|}{ Alongamento } \\
\hline & $\begin{array}{c}\text { média } \pm \\
\text { desvio padrão }\end{array}$ & $\mathrm{S} 1$ & $\mathrm{~S} 2$ & S3 & $\begin{array}{c}\text { média } \pm \\
\text { desvio padrão }\end{array}$ & S1 & $\mathrm{S} 2$ & S3 & $\begin{array}{c}\text { média } \pm \\
\text { desvio padrão }\end{array}$ & $\mathrm{S} 1$ & $\mathrm{~S} 2$ & S3 \\
\hline $\mathrm{IE}$ & $41,3 \pm 13,6$ & 27,6 & 41,5 & 54,1 & $35,2 \pm 8,3$ & 39,3 & 25,7 & 40,6 & $10,3 \pm 10,3$ & 4,0 & 4,9 & 22,2 \\
\hline I & $0,4 \pm 0,7$ & 0,0 & 1,1 & 0,0 & $11,9 \pm 6,8$ & 18,3 & 12,5 & 4,8 & $3,0 \pm 2,0$ & 2,5 & 5,1 & 1,3 \\
\hline DI & $0,0 \pm 0,0$ & 0,0 & 0,0 & 0,0 & $7,0 \pm 1,8$ & 5,2 & 7,2 & 8,7 & $25,4 \pm 13,1$ & 38,7 & 12,6 & 25,0 \\
\hline$D$ & $0,0 \pm 0,0$ & 0,0 & 0,0 & 0,0 & $0,2 \pm 0,3$ & 0,1 & 0,0 & 0,6 & $1,1 \pm 0,3$ & 1,4 & 0,9 & 0,9 \\
\hline $\mathrm{CE}$ & $0,2 \pm 0,2$ & 0,4 & 0,1 & 0,0 & $2,2 \pm 0,5$ & 1,6 & 2,4 & 2,6 & $1,2 \pm 0,7$ & 0,9 & 2,0 & 0,6 \\
\hline $\mathrm{C}$ & $0,0 \pm 0,0$ & 0,0 & 0,0 & 0,0 & $7,6 \pm 7,5$ & 4,8 & 16,1 & 1,9 & $3,9 \pm 6,7$ & 0,0 & 11,6 & 0,0 \\
\hline$A V+E$ & $0,6 \pm 0,7$ & 0,0 & 0,6 & 1,3 & $0,9 \pm 0,7$ & 1,4 & 0,1 & 1,2 & $0,9 \pm 1,0$ & 2,0 & 0,0 & 0,9 \\
\hline $\mathrm{AV}+$ & $0,0 \pm 0,0$ & 0,0 & 0,0 & 0,0 & $0,6 \pm 0,2$ & 0,9 & 0,5 & 0,5 & $0,2 \pm 0,1$ & 0,3 & 0,1 & 0,2 \\
\hline AV-E & $0,1 \pm 0,1$ & 0,0 & 0,1 & 0,0 & $0,2 \pm 0,1$ & 0,1 & 0,3 & 0,2 & $0,0 \pm 0,0$ & 0,0 & 0,0 & 0,0 \\
\hline$A V-$ & $0,0 \pm 0,0$ & 0,0 & 0,0 & 0,0 & $0,1 \pm 0,0$ & 0,1 & 0,2 & 0,1 & $0,0 \pm 0,0$ & 0,0 & 0,0 & 0,0 \\
\hline $\mathrm{QE}$ & $0,2 \pm 0,2$ & 0,0 & 0,4 & 0,2 & $1,1 \pm 0,6$ & 0,5 & 1,2 & 1,7 & $0,8 \pm 0,3$ & 1,1 & 0,5 & 0,9 \\
\hline $\mathrm{Q}$ & $0,1 \pm 0,1$ & 0,0 & 0,1 & 0,0 & $0,9 \pm 0,7$ & 0,8 & 1,7 & 0,2 & $0,2 \pm 0,4$ & 0,0 & 0,7 & 0,0 \\
\hline$A f+E$ & $2,4 \pm 1,5$ & 1,6 & 1,4 & 4,1 & $1,6 \pm 1,6$ & 0,2 & 1,3 & 3,4 & $0,0 \pm 0,1$ & 0,0 & 0,1 & 0,0 \\
\hline Aft & $0,4 \pm 0,7$ & 1,2 & 0,0 & 0,0 & $1,2 \pm 0,8$ & 0,3 & 1,7 & 1,7 & $1,5 \pm 0,8$ & 0,9 & 1,3 & 2,4 \\
\hline Af-E & $0,2 \pm 0,3$ & 0,0 & 0,0 & 0,6 & $0,4 \pm 0,5$ & 0,1 & 0,2 & 1,0 & $0,0 \pm 0,0$ & 0,0 & 0,0 & 0,0 \\
\hline Af- & $0,0 \pm 0,0$ & 0,0 & 0,0 & 0,0 & $0,2 \pm 0,2$ & 0,3 & 0,3 & 0,0 & $0,0 \pm 0,0$ & 0,0 & 0,0 & 0,0 \\
\hline PE & $0,8 \pm 0,5$ & 0,4 & 0,7 & 1,3 & $2,5 \pm 2,0$ & 3,4 & 0,3 & 3,9 & $0,0 \pm 0,0$ & 0,0 & 0,0 & 0,0 \\
\hline$P$ & $0,0 \pm 0,0$ & 0,0 & 0,0 & 0,0 & $0,8 \pm 1,1$ & 2,1 & 0,3 & 0,2 & $0,0 \pm 0,0$ & 0,0 & 0,0 & 0,0 \\
\hline CAE & $0,4 \pm 0,8$ & 0,0 & 0,0 & 1,3 & $0,6 \pm 0,5$ & 0,0 & 1,0 & 0,8 & $1,6 \pm 1,6$ & 0,0 & 1,7 & 3,2 \\
\hline$C A$ & $0,1 \pm 0,2$ & 0,0 & 0,3 & 0,0 & $1,3 \pm 1,5$ & 0,0 & 2,9 & 0,9 & $5,3 \pm 6,7$ & 1,7 & 1,2 & 13,0 \\
\hline COE & $0,0 \pm 0,0$ & 0,0 & 0,0 & 0,0 & $0,0 \pm 0,0$ & 0,0 & 0,0 & 0,0 & $0,0 \pm 0,0$ & 0,0 & 0,0 & 0,0 \\
\hline $\mathrm{CO}$ & $0,0 \pm 0,0$ & 0,0 & 0,0 & 0,0 & $0,0 \pm 0,0$ & 0,0 & 0,0 & 0,0 & $0,8 \pm 1,2$ & 0,0 & 0,3 & 2,1 \\
\hline EFP & $0,0 \pm 0,0$ & 0,0 & 0,0 & 0,0 & $0,0 \pm 0,0$ & 0,0 & 0,0 & 0,0 & $0,0 \pm 0,0$ & 0,0 & 0,0 & 0,0 \\
\hline $\mathrm{EFI}$ & $0,0 \pm 0,0$ & 0,0 & 0,0 & 0,0 & $3,5 \pm 2,7$ & 4,8 & 0,4 & 5,3 & $10,2 \pm 6,6$ & 15,5 & 2,8 & 12,2 \\
\hline$O E$ & $42,7 \pm 15,2$ & 60,2 & 35,9 & 32,0 & $11,1 \pm 3,1$ & 8,5 & 10,4 & 14,4 & $17,0 \pm 9,2$ & 20,3 & 24,0 & 6,6 \\
\hline 0 & $1,0 \pm 0,9$ & 1,2 & 1,8 & 0,0 & $4,8 \pm 4,1$ & 2,8 & 9,5 & 2,0 & $10,5 \pm 11,0$ & 5,1 & 23,1 & 3,2 \\
\hline AIVAE & $0,0 \pm 0,0$ & 0,0 & 0,0 & 0,0 & $0,0 \pm 0,0$ & 0,0 & 0,0 & 0,0 & $0,0 \pm 0,0$ & 0,0 & 0,0 & 0,0 \\
\hline AIVA & $0,7 \pm 0,7$ & 0,8 & 1,4 & 0,0 & $0,2 \pm 0,3$ & 0,1 & 0,5 & 0,0 & $0,0 \pm 0,0$ & 0,0 & 0,0 & 0,0 \\
\hline AIVOE & $0,0 \pm 0,0$ & 0,0 & 0,0 & 0,0 & $0,0 \pm 0,0$ & 0,0 & 0,0 & 0,0 & $0,0 \pm 0,0$ & 0,0 & 0,0 & 0,0 \\
\hline AIVO & $0,0 \pm 0,0$ & 0,0 & 0,0 & 0,0 & $0,0 \pm 0,0$ & 0,0 & 0,0 & 0,0 & $0,0 \pm 0,0$ & 0,0 & 0,0 & 0,0 \\
\hline $\mathrm{GE}$ & $1,0 \pm 1,0$ & 2,0 & 0,1 & 0,7 & $0,5 \pm 0,6$ & 0,4 & 1,1 & 0,0 & $0,0 \pm 0,0$ & 0,0 & 0,0 & 0,0 \\
\hline G & $7,3 \pm 5,5$ & 4,5 & 13,6 & 3,7 & $2,6 \pm 1,0$ & 3,4 & 1,5 & 2,9 & $5,2 \pm 1,9$ & 5,1 & 7,2 & 3,4 \\
\hline $\mathrm{OC}$ & $0,2 \pm 0,4$ & 0,0 & 0,7 & 0,0 & $0,7 \pm 0,3$ & 0,6 & 1,0 & 0,6 & $0,8 \pm 1,0$ & 0,6 & 0,0 & 1,9 \\
\hline
\end{tabular}

S1: Sujeito 1; S2: Sujeito 2; S3: Sujeito 3 
Exercício na Fase Fundamental $(35,19 \pm 8,27 \%)$ e a DI no Alongamento $(25,43 \pm 13,06 \%)$.

Em média, mais de $2 / 3$ do Aquecimento $(84,02 \%)$ são ocupados com os comportamentos O E $(42,70 \pm 15,24 \%)$ e IE $(41,32 \pm 13,59 \%)$. Em média, mais de $2 / 3$ da Fase Fundamental $(72,71 \%)$ são ocupados com os comportamentos IE $(35,19 \pm 8,27 \%), \quad$ I $(11,86 \pm 6,79 \%), O E$ $(11,08 \pm 3,04 \%), C(7,55 \pm 7,50 \%)$ e DI $(7,03 \pm 1,78 \%)$. Em média, mais de $2 / 3$ do Alongamento $(73,38 \%)$ são ocupados com DI $(25,43 \pm 13,06 \%), 0$ E $(16,99 \pm 9,17 \%)$, O $(10,46 \pm 10,98 \%), \operatorname{IE}(10,34 \pm 10,30 \%)$ e Exercício Independente $(10,16 \pm 6,63 \%)$.

No Aquecimento existe uma maior percentagem de $A f+E$ em qualquer uma das instrutoras $(2,37 \pm 1,48 \%)$, comparativamente às outras fases da aula. Talvez, as instruto ras queiram criar um clima positivo logo no início da aula, de forma a motivar os alunos para a mesma.

É na Fase Fundamental que os comportamentos PE e $P$ aparecem com uma média percentual mais elevada, respectivamente $2,54 \pm 1,48 \%$ e $0,84 \pm 1,08 \%$, comparativamente às outras fases da aula. É também na Fase Fundamental que os alunos realizam um esforço físico mais intenso, pelo que é natural que as instrutoras adotem mais este tipo de comportamento nesta fase da aula, de forma a levar os alunos a manterem a atividade incentivando-os a suportar o esforço. Note-se que o encorajamento para o esforço é uma das estratégias que, segundo $\mathrm{Carron}^{33}$, os instruto res devem utilizar para fidelizar os clientes ao exercício, sendo a Fase Fundamental propícia para tal.

Quadro 5 - Percentagens de cada dimensão de comportamentos Com Exercício e Sem Exercício, na totalidade da aula

\begin{tabular}{|c|c|c|c|c|c|}
\hline Dimensão de Comportamento & & média \pm desvio padrão & $\mathrm{S} 1$ & $\mathrm{~S} 2$ & $\mathrm{S3}$ \\
\hline \multirow{2}{*}{ Instrução } & Com Exercício & $44,9 \pm 10,0$ & 46,1 & 34,3 & 54,3 \\
\hline & Sem Exercício & $15,8 \pm 9,1$ & 19,9 & 22,2 & 5,3 \\
\hline \multirow{2}{*}{ Interação } & Com Exercício & $4,4 \pm 2,8$ & 3,1 & 2,5 & 7,6 \\
\hline & Sem Exercício & $3,7 \pm 1,2$ & 2,6 & 3,6 & 4,9 \\
\hline \multirow{2}{*}{ Atividade } & Com Exercício & $4,0 \pm 2,8$ & 5,8 & 0,8 & 5,4 \\
\hline & Sem Exercício & $0,0 \pm 0,0$ & 0,0 & 0,0 & 0,0 \\
\hline \multirow{2}{*}{ Controle } & Com Exercício & $16,7 \pm 1,9$ & 14,7 & 18,5 & 16,7 \\
\hline & Sem Exercício & $5,5 \pm 5,3$ & 3,1 & 11,5 & 1,8 \\
\hline \multirow{2}{*}{ O rganização } & Com Exercício & $0,4 \pm 0,3$ & 0,5 & 0,7 & 0,2 \\
\hline & Sem Exercício & $4,0 \pm 1,1$ & 3,7 & 5,2 & 3,2 \\
\hline \multirow{2}{*}{ O utros Comportamentos } & Com Exercício & $0,0 \pm 0,0$ & 0,0 & 0,0 & 0,0 \\
\hline & Sem Exercício & $0,7 \pm 0,1$ & 0,6 & 0,7 & 0,7 \\
\hline
\end{tabular}

S1: Sujeito 1; S2: Sujeito 2; S3: Sujeito 3

Quadro 6 - Percentagens de comportamento Com Exercício e Sem Exercício, na totalidade da aula, nas suas diferentes fases e em diferentes tipos de exercícios, e percentagem total de tempo em cada fase da aula e em cada tipo de exercício

\begin{tabular}{|c|c|c|c|c|c|c|}
\hline & & Comportamentos & média \pm desvio padrão & S1 & S2 & S3 \\
\hline \multirow{9}{*}{ 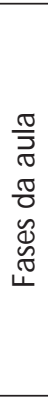 } & \multirow{3}{*}{ Aquecimento } & Com Exercício & $89,8 \pm 8,0$ & 92,3 & 80,9 & 96,3 \\
\hline & & Sem Exercício & $10,2 \pm 8,0$ & 7,7 & 19,1 & 3,7 \\
\hline & & total tempo & $16,8 \pm 6,7$ & 9,1 & 20,3 & 21,0 \\
\hline & \multirow{3}{*}{ Fase Fundamental } & Com Exercício & $67,1 \pm 16,6$ & 65,5 & 51,4 & 84,4 \\
\hline & & Sem Exercício & $32,9 \pm 16,6$ & 34,5 & 48,6 & 15,6 \\
\hline & & total tempo & $65,6 \pm 10,7$ & 77,8 & 58,0 & 60,9 \\
\hline & \multirow{3}{*}{ Alongamento } & Com Exercício & $68,6 \pm 17,5$ & 83,9 & 49,5 & 72,4 \\
\hline & & Sem Exercício & $31,4 \pm 17,5$ & 16,1 & 50,5 & 27,6 \\
\hline & & total tempo & $17,7 \pm 4,3$ & 13,1 & 21,7 & 18,2 \\
\hline \multirow{6}{*}{ 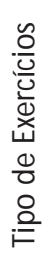 } & \multirow{4}{*}{ Exercícios com Boa Visualização } & Com Exercício & $82,0 \pm 4,5$ & 83,7 & 76,9 & 85,4 \\
\hline & & Sem Exercício & $18,0 \pm 4,5$ & 16,3 & 23,2 & 14,6 \\
\hline & & total tempo & $57,3 \pm 19,5$ & 35,2 & 65,0 & 71,7 \\
\hline & & Com Exercício & $55,4 \pm 32,2$ & 63,2 & 20,0 & 83,1 \\
\hline & \multirow[t]{2}{*}{ Exercícios com Má Visualização } & Sem Exercício & $44,6 \pm 32,2$ & 36,8 & 80,0 & 16,9 \\
\hline & & total tempo & $42,7 \pm 19,5$ & 64,8 & 35,0 & 28,3 \\
\hline \multirow{2}{*}{\multicolumn{2}{|c|}{ total aula }} & Com Exercício & $70,7 \pm 13,9$ & 70,4 & 57,0 & 84,7 \\
\hline & & Sem Exercício & $29,3 \pm 13,9$ & 29,6 & 43,0 & 15,3 \\
\hline
\end{tabular}

S1: Sujeito 1; S2: Sujeito 2; S3: Sujeito 3 
O Alongamento é a fase da aula onde, em média, surgem mais C onversas Com os Alunos, estejam as instrutoras em exercício ou não $(1,64 \pm 1,60 \%$ e 5,30 6 6,70\%, respectivamente).

É no Aquecimento, seguido da fase de Alongamento, que os comportamentos de $G$ surgem com mais frequência, respectivamente com média de $7,26 \pm 5,51 \%$ e de $5,24 \pm 1,90 \%$.

Comparando os resultados deste estudo com o estudo de Lacy \& Martin ${ }^{13}$, acerca dos comportamentos dos treinadores de voleibol, podemos constatar que 0 comportamento O bservação, no nosso estudo Com Exercício, foi também o que em média surgiu com maior percentagem no Alongamento, embora a IE tenha uma elevada predominância no nosso estudo e não no de Lacy \& Martin7. Q uanto à fase de Preparação Física, a qual é a única que pode permitir alguma comparação com a Fase Fundamental de uma aula de localizada, no estudo de Lacy $\&$ Martin ${ }^{13}$ predominam os comportamentos de Silêncio (O bservação), G estão e Instrução Concorrente, e no presente estudo também prevalecem os comportamentos de Informação (Com e Sem Exercício) e de 0 bservação (Com Exercício), mas não os de $\mathrm{G}$ estão.

Naturalmente, na dimensão Atividade não existem comportamentos Sem Exercício (Q uadro 5). O s sujeitos

Quadro 7 - Percentagens de cada categoria de comportamentos, em diferentes tipos de exercícios (Com Boa Visualização e Sem Boa Visualização)

\begin{tabular}{|c|c|c|c|c|c|c|c|c|}
\hline \multirow[b]{2}{*}{ Comport. } & \multicolumn{4}{|c|}{ Exercícios com Boa Visualização } & \multicolumn{4}{|c|}{ Exercícios com Má Visualização } \\
\hline & $\begin{array}{c}\text { média } \pm \text { desvio } \\
\text { padrão }\end{array}$ & S1 & $\mathrm{S} 2$ & S3 & $\begin{array}{c}\text { média } \pm \text { desvio } \\
\text { padrão }\end{array}$ & $\mathrm{S} 1$ & $\mathrm{~S} 2$ & S3 \\
\hline IE & $39,3 \pm 5,4$ & 40,2 & 33,5 & 44,1 & $22,6 \pm 13,2$ & 30,0 & 7,3 & 30,4 \\
\hline | & $4,8 \pm 0,6$ & 5,2 & 5,2 & 4,1 & $11,8 \pm 9,9$ & 19,7 & 14,9 & 0,7 \\
\hline DI & $6,7 \pm 1,0$ & 5,9 & 6,3 & 7,9 & $11,3 \pm 3,5$ & 10,9 & 8,0 & 15,0 \\
\hline D & $0,4 \pm 0,3$ & 0,7 & 0,3 & 0,1 & $0,6 \pm 1,0$ & 0,0 & 0,0 & 1,7 \\
\hline CE & $1,5 \pm 0,6$ & 1,3 & 2,2 & 1,1 & $1,9 \pm 1,0$ & 1,4 & 1,1 & 3,0 \\
\hline C & $3,0 \pm 2,1$ & 2,0 & 5,5 & 1,6 & $9,4 \pm 12,5$ & 4,6 & 23,6 & 0,0 \\
\hline$A v+E$ & $1,1 \pm 0,6$ & 1,3 & 0,2 & 1,4 & $0,7 \pm 0,7$ & 1,4 & 0,0 & 0,7 \\
\hline Av+ & $0,3 \pm 0,1$ & 0,2 & 0,2 & 0,4 & $0,5 \pm 0,5$ & 1,0 & 0,7 & 0,0 \\
\hline$A v-E$ & $0,2 \pm 0,1$ & 0,2 & 0,3 & 0,2 & $0,0 \pm 0,0$ & 0,0 & 0,0 & 0,0 \\
\hline Av- & $0,0 \pm 0,1$ & 0,0 & 0,0 & 0,1 & $0,1 \pm 0,1$ & 0,1 & 0,2 & 0,0 \\
\hline QE & $1,2 \pm 0,2$ & 1,0 & 1,3 & 1,3 & $0,6 \pm 0,6$ & 0,3 & 0,2 & 1,2 \\
\hline Q & $0,4 \pm 0,4$ & 0,1 & 0,9 & 0,2 & $0,8 \pm 0,8$ & 0,9 & 1,6 & 0,0 \\
\hline$A f+E$ & $2,0 \pm 1,6$ & 0,5 & 1,7 & 3,7 & $0,3 \pm 0,4$ & 0,2 & 0,0 & 0,8 \\
\hline Aft+ & $0,9 \pm 0,5$ & 0,6 & 0,6 & 1,4 & $1,5 \pm 1,0$ & 0,4 & 2,4 & 1,5 \\
\hline$A f-E$ & $0,4 \pm 0,5$ & 0,0 & 0,2 & 1,0 & $0,0 \pm 0,1$ & 0,1 & 0,0 & 0,0 \\
\hline Af- & $0,0 \pm 0,1$ & 0,0 & 0,1 & 0,0 & $0,3 \pm 0,2$ & 0,3 & 0,4 & 0,0 \\
\hline PE & $2,0 \pm 1,4$ & 3,1 & 0,5 & 2,6 & $1,8 \pm 1,5$ & 2,5 & 0,0 & 2,8 \\
\hline$P$ & $0,3 \pm 0,0$ & 0,6 & 0,0 & 0,2 & $0,9 \pm 1,2$ & 2,2 & 0,4 & 0,0 \\
\hline CAE & $1,0 \pm 0,9$ & 0,0 & 1,4 & 1,7 & $0,2 \pm 0,2$ & 0,0 & 0,2 & 0,4 \\
\hline$C A$ & $0,6 \pm 0,3$ & 0,6 & 0,3 & 0,9 & $4,4 \pm 4,1$ & 0,0 & 5,2 & 8,0 \\
\hline $\mathrm{COE}$ & $0,0 \pm 0,0$ & 0,0 & 0,0 & 0,0 & $0,0 \pm 0,0$ & 0,0 & 0,0 & 0,0 \\
\hline $\mathrm{CO}$ & $0,0 \pm 0,0$ & 0,0 & 0,0 & 0,0 & $0,5 \pm 0,8$ & 0,0 & 0,2 & 1,4 \\
\hline EFP & $0,0 \pm 0,0$ & 0,0 & 0,0 & 0,0 & $0,0 \pm 0,0$ & 0,0 & 0,0 & 0,0 \\
\hline EFI & $1,0 \pm 1,0$ & 1,0 & 0,0 & 2,0 & $8,4 \pm 6,0$ & 8,4 & 2,4 & 14,3 \\
\hline OE & $24,7 \pm 5,6$ & 27,9 & 28,0 & 18,2 & $7,1 \pm 6,0$ & 7,6 & 0,9 & 12,9 \\
\hline 0 & $2,8 \pm 1,4$ & 2,4 & 4,3 & 1,6 & $9,5 \pm 11,8$ & 3,3 & 23,1 & 2,2 \\
\hline AIVAE & $0,0 \pm 0,0$ & 0,0 & 0,0 & 0,0 & $0,0 \pm 0,0$ & 0,0 & 0,0 & 0,0 \\
\hline AIVA & $0,2 \pm 0,2$ & 0,2 & 0,4 & 0,0 & $0,3 \pm 0,4$ & 0,1 & 0,8 & 0,0 \\
\hline AIVOE & $0,0 \pm 0,0$ & 0,0 & 0,0 & 0,0 & $0,0 \pm 0,0$ & 0,0 & 0,0 & 0,0 \\
\hline AIVO & $0,0 \pm 0,0$ & 0,0 & 0,0 & 0,0 & $0,0 \pm 0,0$ & 0,0 & 0,0 & 0,0 \\
\hline GE & $0,7 \pm 0,4$ & 0,7 & 1,1 & 0,2 & $0,1 \pm 0,2$ & 0,3 & 0,0 & 0,0 \\
\hline G & $4,2 \pm 1,1$ & 3,7 & 5,5 & 3,5 & $3,5 \pm 1,2$ & 3,8 & 4,6 & 2,2 \\
\hline $\mathrm{OC}$ & $0,5 \pm 0,2$ & 0,6 & 0,2 & 0,6 & $1,1 \pm 0,6$ & 0,5 & 1,7 & 1,0 \\
\hline
\end{tabular}

S1: Sujeito 1; S2: Sujeito 2; S3: Sujeito 3 
estão maioritariamente em exercício nas dimensões Instrução, Interação e Controle e maioritariamente sem estar em exercício nas dimensões 0 rganização e O C. É natural que todos os sujeitos tenham mais comportamentos organizativos quando não estão a realizar exercício, sendo lógico que estes ocorram predominantemente antes ou depois da realização dos exercícios, e para além disso não é fácil compatibilizar estes dois comportamentos, designadamente quando se pretende manipular materiais.

Como se pode observar no Q uadro 6, todas instrutoras apresentam uma maior percentagem de comportamentos Com Exercício em qualquer das fases da aula, podendo esta ser uma estratégia no sentido de servir de modelo e/ ou motivar os alunos para se empenharem nos exercícios. No entanto, esta percentagem é superior no Aquecimento, comparativamente à Fase Fundamental ou ao Alongamento.

Exceptuando as categorias que não se subdividem em Com Exercício e Sem Exercício (DI, D, EFP, EFI e O C), apenas as categorias Correção, Conversas, seja Com Alunos ou $\mathrm{C}$ om $\mathrm{O}$ utros, Atenção às Intervenções Verbais dos Alunos e G estão, apresentam valores percentuais médios superiores Sem Exercício do que Com Exercício ( $Q$ uadro 2), parecendo que os instrutores optam por corrigir, conversar e estar atentos aos alunos, assim como realizar comportamentos o rganizativos, quando não estão a realizar exercício.

Relativamente ao tipo de exercícios propostos, todas as instrutoras, embora umas mais do que outras, têm uma menor quantidade de comportamentos Com Exercício nos exercícios que, devido ao seu posicionamento, não thes permitem ter uma boa visualização dos alunos, comparativamente aos que permitem ter uma boa visualização. Parece que, quando são propostos exercícios aos alunos que as instrutoras, ao os realizarem, não conseguem observar bem os alunos, estas deixam de ter tantos comportamentos $\mathrm{Com}$ Exercício, aumentando os seus comportamentos Sem Exercício. Talvez isto ocorra pelo fato das instrutoras pararem de fazer exercício, mudando a sua posição de forma a poderem visualizar bem os alunos, por exemplo para os observar, já que a média do comportamento 0 aumenta de $2,79 \%$ para 9,53\% (Q uadro 7).

Em todas as instrutoras a maior parte da aula é, naturalmente, ocupada com a Fase Fundamental $(65,55 \pm 10,69 \%)$.

Apesar de, em média, as instrutoras utilizarem mais exercícios que permitem uma boa visualização do que com má visualização, uma das três instrutoras faz o contrário. Note-se que não se considera negativo 0 fato de serem propostos exercícios que não permitem uma boa visualização, pois o posicionamento escolhido pode estar relacionado com o fato de haver necessidade de adotar determinadas posições para poder trabalhar eficazmente determinados grupos musculares ou atingir determinado objetivo, ou com o fato de se pretender variar os exercícios para trabalhar um determinado grupo muscular.

No Q uadro 7, com exceção do comportamento G, nos exercícios com má visualização todos os comportamentos Sem Exercício, em média, têm uma maior percentagem, comparativamente aos exercícios com boa visualização. Por outro lado, com exceção dos comportamentos DI, D, CE e Exercício Independente, nos exercícios com boa visualização todos os comportamentos Com Exercício, em média, têm uma maior percentagem, comparativamente aos exercícios com má visualização.

Q uando são propostos exercícios em que existe má visualização dos alunos por parte das instrutoras, durante a realização dos mesmos, a média do comportamento O E diminui de $24,68 \%$ para $7,13 \%$ e a média do comportamento 0 aumenta de $2,79 \%$ para $9,53 \%$, passando elas a observar menos os alunos, quer estas estejam em exercício ou não. Por outro lado, nesta situação, a média do comportamento de Exercício Independente aumenta de $0,97 \%$ para $8,35 \%$, parecendo que as instrutoras passam a observar menos para realizar mais Exercício Independente, o que, eventualmente, poderá ser devido ao fato destas não quererem ser um mau modelo ou não se sentirem confortáveis quando adotam uma posição incorreta com a cabeça, por exemplo em hiperextensão ou em rotação.

0 utro aspecto a realçar é 0 fato das instrutoras, quando propõem aos alunos exercícios que não thes permitem ter uma visualização durante a realização dos mesmos, para além de reduzirem o tempo em exercício, passam a corrigir mais os alunos, já que a média do comportamento de C aumenta de 3,01\% para $9,41 \%$. Será que o fato das instrutoras realizarem exercício leva a que sejam reduzidos os comportamentos de correção dos alunos, os quais, segundo Cunha ${ }^{\mathbf{3 8}}$, são importantes na obtenção do sucesso na aprendizagem?

É ainda de salientar a ocorrência de um aumento da DI, de $6,68 \%$ para $11,27 \%$, e de uma redução do total de Informação (Com Exercício e Sem Exercício) de 44,10\% $(39,29 \%+4,81 \%)$ para $34,34 \%(22,58 \%+11,76 \%)$, quando são propostos exercícios em que as instrutoras têm uma má visualização dos alunos durante a sua execução. Serão os exercícios mais complexos ou será mais difícil a observação dos exercícios por parte dos alunos, por exemplo devido ao seu posicionamento, levando as instruto ras a terem um maior cuidado na sua explicação, deixando estas de apenas apresentar informação para também demonstrar? 
Dado que o total das Conversas Sem Exercício aumentou de $0,60 \%$ para $4,39 \%$ quando da realização de exercícios com má visualização, terá sido coincidência ou o fato das instrutoras deixarem de realizar exercício físico permite-Ihes conversar mais com os alunos? 0 fato dos instrutores estarem a realizar exercício possivelmente não facilita o desenvolvimento de conversas, até porque os instrutores têm outras funções pedagógicas importantes a desempenhar, como por exemplo fornecer feedbacks. $0 \mathrm{~s}$ feedbacks são importantes quer para melhorar 0 desempenho dos alunos quer para motivar ${ }^{33,37,38}, 0$ que leva os sujeitos a manterem-se na atividade, mas também as conversas são importantes para a adesão ao exercício ${ }^{33}$.

Com este estudo, conseguiu-se realizar uma aplicação piloto do Sistema de O bservação do Comportamento dos Instrutores de Fitness - Aulas de Grupo, ao nível das instrutoras de localizada, com a qual concluiu-se o seguinte:

- Quando confrontados os resultados deste estudo com os de outras pesquisas ${ }^{8,11,12,13,14,15,16,16,18,34,35}$ verifica-se que, independentemente do contexto, os dois principais comportamentos dos professores, treinadores ou instrutores são a Informação e/ou a O bservação, parecendo que os restantes comportamentos apresentam variações em termos de ocorrência;

- O s comportamentos COE, EFP, AIVAE, AIVOE e AIVO, nunca ocorreram em nenhum dos sujeitos da amostra;

- O s comportamentos positivos predominam em relação aos negativos, o que parece ser benéfico, já que os comportamentos positivos parecem favorecer a motivação e fidelização dos clientes ao exercício ${ }^{33,37,38}$.

- As instrutoras utilizam os comportamentos Avaliação Positiva, Afetividade Positiva, Pressão e Conversas Com Alunos, o que, segundo Carron et al. ${ }^{33}$, são importantes estratégias pedagógicas para reter os clientes;

- O s comportamentos evidenciam uma variação na sua ocorrência de sujeito para sujeito;

- O s comportamentos parecem mudar a sua ocorrência de acordo com as fases da aula;

- Os comportamentos aparentam ser influenciados pela posição de realização dos exercícios;

- As instrutoras, durante a aula, passam a maior parte do seu tempo a realizar exercício físico $(70,70 \pm 13,88 \%)$, o que pode ser problemático para a sua saúde ${ }^{39}$.

Mais uma vez relembramos que, como os dados deste estudo são referentes apenas a uma aula de localizada, de cada uma das três instrutoras de fitness, estes não são representativos nem do perfil de cada uma das instrutoras, nem do perfil dos instrutores de fitness em geral, não podendo assim os dados ser generalizados.

Com a aplicação do sistema de observação utilizado é possível fazer uma análise descritiva e comparativa dos comportamentos dos instruto res de fitness, sendo possível verificar qual a influência que algumas variáveis podem ter nas várias categorias de comportamentos.

\section{RECOMENDAÇÕES}

Teria sido interessante ter uma amostra maior e ter observado mais aulas de cada instrutora, o que teria permitido tirar conclusões um pouco mais consistentes e não apenas referentes às ocorrências de uma aula de cada instrutora.

$\mathrm{N}$ a sequência deste estudo, julga-se pertinente deixar as seguintes sugestões para futuras investigações:

- Realizar entrevistas de estimulação de memória com visualização de vídeo das aulas lecionadas pelos instrutores, para perceber a opinião dos instrutores relativamente ao porquê de determinado tipo de comportamentos que estes têm;

- Realizar entrevistas ou questionários com os alunos, para saber qual o tipo de comportamento que preferem que os seus instrutores tenham;

- Estudar em profundidade qual o tipo de conversa que os instrutores têm com os alunos, no início e fim da aula e na fase de prática física;

- Estudar em profundidade os comportamentos de instrução dos instrutores;

- Estudar quais as seqüências de comportamentos existentes nos instrutores;

- Verificar se os instrutores apresentam uma consistência, relativamente aos seus comportamentos em várias aulas, de um mesmo horário de determinada atividade, tentando traçar um perfil de comportamentos para cada um deles;

- Verificar se existe um perfil de instrutor de uma determinada atividade, ou se estes apresentam um perfil individual;

- Verificar se os comportamentos dos instruto res estão relacionados com os estilos de ensino utilizados;

- Verificar se o perfil dos instrutores varia de acordo com outras variáveis, quais sejam as atividades lecionadas, a região do país, os ginásios, os horários, o número de alunos, o nível dos alunos, a formação inicial dos instrutores, a experiência profissional dos instrutores, o gênero dos instrutores, entre outros.

Resumindo, ainda há muito por estudar, relativamente ao comportamento dos instrutores de aulas de grupo de fitness. Espera-se que este trabalho tenha sido um contributo para o desenvolvimento de outros estudos em 
Pedagogia do Desporto aplicados à área do fitness, a qual tem ainda muito por explorar. Espera-se que este estudo possa assim ser mais uma semente para o florescer do conhecimento acerca dos aspectos pedagógicos na área do fitness.

\section{REFERÊNCIAS}

1. Potrac $P$, Brewer $C$ J, Jones R, Armour K, Hoff J. Toward an holistic understanding of the coaching process. Q uest. 2000;52(2):186-99.

2. Sarmento P, Veiga AL, Rosado A, Rodrigues J, Ferreira V. Pedagogia do Desporto. Instrumentos de Observação Sistemática da Educação Física e Desporto. Cruz Quebrada: Edições da Faculdade de Motricidade Humana; 1998.

3. De Marco GM, Mancini VH, Wuest DA, Schempp PG. Becoming reacquainted with a once familiar and still valuable tool: systematic observation meth odology revisited. I J Phys Educ. 1996;33(1):17-26.

4. Mars H. Systematic observation: an introduction. In: Darst PW, Zakrajsek DB, Mancini VH, editores. Analyzing physical education and sport instruction. Champaign, II: Human Kinetics; 1989.

5. Martin G, Hrycaiko D. Effective behavioral coaching: what's it all about? J Sport Psychol. 1983;5:8-20.

6. Costa FC. 0 sucesso pedagógico em educação física. estudo das condições e fatores de ensino-aprendizagem associados ao êxito numa unidade de ensino. [tese]. Cruz Q uebrada: Instituto Superior de Educação Física; 1988.

7. Lacy AC, Darst PW. evolution of a systematic observation system: the asu coaching observation instrument. J Teach Phys Educ. 1984;3(3):59-66.

8. Rodrigues J, Rosado A, Sarmento P, Ferreira V, Veiga AL. O Sistema de observação do comportamento do treinador e do atleta (sota). estudo ilustrativo em natação e voleibol. In: Sarmento P, editor. Pedagogia do desporto. Estudos 1. Cruz Q uebrada: Edições da Faculdade de Motricidade Humana 1992

9. Smith RE, Smoll FL, Hunt E. A system for the behavioral assessment of athletic coaches. Res Q. 1977;48(2):401-7.

10. Lacy AC, Goldston PD. Behavior analysis of male and female coaches in high school girls' basketball. J Sport Behav. 1990;13(1):29-39.

11. Bloom GA, Crumpton R, Anderson JE. A systematic observation study of the teaching behaviors of an expert basketball coach. Sport Psychol. 1999;13(2):157-70.

12. Claxton DB. A systematic observation of more and less successful high school tennis coaches. J Teach Phys Educ. 1988;7(4):302-10.

13. Lacy AC, Martin DL. Analysis of starter/nonstarter motor-skill engagement and coaching behaviors in collegiate women's volleyball. J Teach Phys Educ. 1994;13(2):95-107.

14. Massey CD, Maneval MW, Phillips J, Vincent], White G, Zoeller B. An analysis of teaching and coaching behaviors of elite strength and conditioning coaches. J Strength Cond Res. 2002;16(3):456-60.

15. Rodrigues J. 0 comportamento do treinador. Estudo da influência do objetivo dos treinos e do nível de prática dos atletas na atividade pedagógica do treinador de voleibol. [tese]. Cruz Q uebrada: Edições da Faculdade de Motricidade Humana; 1995.

16. Santos R, Rodrigues J. A atividade pedagógica do treinador de jovens em ténis. Desp Investig Ciênc. 2002;0:11-20.

17. Seagrave JO, Ciancio CA. An observational study of a successful pop warner football coach. J Teach Phys Educ. 1990;9(4):294-306.

18. Sequeira P, Hanke U, Rodrigues ]. 0 comportamento do treinador de altacompetição de handebol no treino e na competição. Itinerários. 2006;2a Série(2):81-99.

19. Brewer CJ, Jones RL. A five-stage process for establishing contextually valid systematic observation instruments: the case of rugby union. Sport Pshychol. 2002;16(2):138-59.
20. Franco S. Observação do comportamento pedagógico dos instrutores de aulas de grupo de fitness [tese]. Lleida: Institut $\mathrm{N}$ acional d'Educació Física de Catalunya; 2004.

21. Francis LL, Seibert RJ. Teaching a group exercise class. In: ACE, editor. Group fitness instructor manual. San Diego: American Council on Exercise; 2000.

22. Hill M, Hill A. Investigação por questionário. Lisboa: Edições Silabo; 2002.

23. Malek MH, Nalbone DP, Berger DE, Coburn JW. Importance of health sciences education for personal fitness trainers. J Strength Cond Res. 2002;16(1):19-24.

24. Petrica J, Sarmento P, Videira M. A instrução. Análise dos comportamentos de instrução em professores preparados por modelos distintos. Ludens Ciênc Desp. 2004;17(4):11-9.

25. Piéron M. Para una enseñanza eficaz de las atividades físico-deportivas. Barcelona: INDE Publicaciones; 1999.

26. Rosado A, Pereira A, Fernandes A, Martins C. Observação do comportamento do professor. Comparação de dois grupos de professores com especializações profissionais diferenciadas no ensino do atletismo. In: Sarmento P, editor. Pedagogia do desporto estudos 1-2-3 (edição especial conjunta). Cruz Q uebrada: Edições da Faculdade de Motricidade Humana; 1997.

27. Moreira MIFV, Januário C. Análise das decisões pré-interactivas e interactivas em professores "expert" e principiantes relativamente à dimensão instrução. In: Ferreira V, Sarmento P, editores. Formação desportiva perspectivas de estudo nos contextos escolar e desportivo. Cruz Quebrada: Edições da Faculdade de Motricidade Humana; 2004

28. Sarmento P, Rodrigues J, Veiga AL, Rosado A, Ferreira V. Análise do comportamento do treinador. Estudo comparativo em modalidades contextualmente diferenciadas. Ludens - Ciênc Desp. 1993;13(1):20-3.

29. Anguera MT, Blanco Á, Losada JL. Diseños observacionales, cuestión clave en el proceso de la metodología observacional. Metodol Cienc Comport. 2001;3(2):135-60.

30. Mars H. Basic recording tatics. In: Darst PW, Zakrajsek DB, Mancini VH, editores. Analysing physical education and sport instruction. Champaign, Illinois: Human Kinetics; 1989.

31. Mars H. O bserver reliability: issues and procedures. In: Darst PW, Zakrajsek DB, Mancini VH, editores. Analysing physical education and sport instruction. Champaign, Illinois: Human Kinetics; 1989.

32. Pestana MH, Gageiro JN. Análise de dados para ciências sociais - A complementaridade do SPSS. Lisboa: Edições Silabo; 2003.

33. Carron AV, Hausenblas HA, Estabrooks PA. Social influence and exercise involvement. In: Bull SJ, editor. Adherence issues in sport and exercise. West Sussex: John Wiley \& Sons; 1999.

34. Brito A, Rodrigues J. As decisões e os comportamentos do treinador de ginástica artística. Desp Investig Ciênc. 2002;1:21-39.

35. Potrac $P$, Jones $R$, Armour K. It's all about getting respect': the coaching behaviors of an expert english soccer coach. Sport Educ Soc. 2002;7(2):183202.

36. Schmidt RA, Lee TD. Motor control and learning. Champaign, II: Human Kinetics; 1999.

37. Mageau GA, Vallerand RJ. The coach-athlete relationship: a motivational model. J Sport Sci. 2003;21:883-904.

38. Cunha FA. Feedback como instrumento pedagógico. EducaçãoFísica.org [serial na internet]. 2004 [citado em 2008 abr 10]; [cerca de 19 telas]. Disponível em: http://educacaofisica.org/joomla/index.php?option=com_c ontent\&task $=$ view $\& i d=147 \& \mid$ temid $=2$

39. Rocha RS, Brandão F, Cipriano H, Asseiceiro C, Veloso A. Prevalência de perturbações musculoesqueléticas em instrutores de fitness. Estudo exploratório. Desp Investig Ciênc. 2003:3:89-106.

Recebido: 12/04/2008 - Aceito: 22/06/2008 